\title{
Racionalidade substantiva e racionalidade instrumental em licitações públicas: ganhos e perdas para a seleção da proposta mais vantajosa
}

\author{
VANILSON VIANA CARDOSO ${ }^{1}$ \\ AirTON AdELAR MUELLER ${ }^{1}$ \\ ${ }^{1}$ Universidade Regional do Noroeste do Estado do Rio Grande do Sul (UNIJUÍ), IJUÍ - RS, BrasiL
}

\begin{abstract}
Resumo
Este artigo foi desenvolvido com o objetivo de identificar elementos nos processos licitatórios da administração pública, que mantêm relação com a racionalidade instrumental e/ou substantiva. Os resultados apontam que o tensionamento entre essas duas abordagens contribui para a avaliação crítica das decisões do gestor público, no que tange à definição dos critérios de habilitação e qualificação técnica exigidos das empresas licitantes. Ao passo que o certame deveria promover a concorrência de preços e proporcionar a melhor contratação, o excesso de instrumental de que se revestem os atos discricionários e vinculados resulta, com base nos resultados obtidos, em deficiências substanciais para o funcionamento da administração pública, que maculam a supremacia do interesse público. Para a elaboração do estudo, adotou-se como fundamentação teórica um conjunto de precedentes da literatura que discute a racionalidade nas organizações, bem como o processo de tensão entre a abordagem instrumental e a substantiva. Trata-se de pesquisa qualitativa, realizada mediante análise documental, revisão bibliográfica e observação não participante. Entre os anos de 2017 e 2019, acompanharam-se as sessões públicas de licitações de um município do noroeste do Estado do Rio Grande do Sul, com população de cerca de 60 mil habitantes. Em suma, constatou-se que o poder público, ao se pautar demasiadamente pela racionalidade instrumental durante a condução dos processos licitatórios, fomenta uma disputa de interesses particulares dos licitantes, alheios ao interesse público, o que pode desencadear uma série de problemas para a administração pública.
\end{abstract}

Palavras-chave: Racionalidade instrumental. Racionalidade substantiva. Administração pública. Licitações. Melhor contratação.

\section{Substantive and instrumental rationality in public bidding: gains and losses in the selection of the most advantageous bid}

\begin{abstract}
This article aims to identify elements present in the bidding processes of public administration related to instrumental and/or substantive rationality. The results show that the tensions between these two approaches contribute to the critical evaluation of the public manager's decisions on defining the licensing and technical qualification criteria required by the bidding companies. Although the event should promote price competition and provide the best contract, the excess of instrumental rationality in the discretionary and linked acts result in substantial deficiencies for the functioning of the public administration, which goes against the public interest. The study's theoretical foundation is based on the literature about rationality in the organizations and the tensions between the instrumental and substantive rationality. This is a qualitative research, performed through document analysis, bibliographical research, and non-participant observation. Public bidding sessions of a town in the Northwest of the state of Rio Grande do Sul with a population of about 60,000 inhabitants were observed between 2017 and 2019 . The research showed that the government's bidding processes are overly guided by instrumental rationality. This characteristic promotes disputes focused on bidders' private interests at the expense of the public interest, which may trigger a series of problems to the public administration.
\end{abstract}

Keywords: Instrumental and substantive rationality. Public administration. Biddings. Better contract.

Racionalidad sustantiva y racionalidad instrumental en licitaciones públicas: ganancias y pérdidas para la selección de la propuesta más ventajosa

\section{Resumen}

Este artículo fue desarrollado con el objetivo de identificar elementos en los procesos de licitación de la administración pública, que están relacionados con la racionalidad instrumental y/o sustantiva. Los resultados muestran que la tensión entre estos dos enfoques contribuye a la evaluación crítica de las decisiones del gestor público en lo que se refiere a la definición de los criterios de capacidad y calificación técnica exigidos a las empresas licitadoras. Si bien la licitación debería promover la competencia de precios y proporcionar la mejor contratación, el exceso de instrumental que reviste los actos discrecionales y vinculados resulta, de acuerdo con los resultados obtenidos, en deficiencias sustanciales para el funcionamiento de la administración pública que empañan la supremacía del interés público. Para la elaboración del estudio se adoptó como fundamentación teórica un conjunto de precedentes de la literatura que discute la racionalidad en las organizaciones, así como el proceso de tensión entre el enfoque instrumental y el sustantivo. Se trata de una investigación cualitativa, realizada a través de análisis de documentos, revisión bibliográfica y observación no participante. Entre 2017 y 2019, se siguieron las sesiones públicas de licitaciones de un municipio del noroeste del estado de Río Grande do Sul, con una población de alrededor de 60 mil habitantes. En suma, se constató que el poder público, al guiarse excesivamente por la racionalidad instrumental durante la conducción de los procesos licitatorios, fomenta una disputa de intereses privados de los licitadores, ajenos al interés público, lo que puede desencadenar una serie de problemas para la administración pública.

Palabras clave: Racionalidad instrumental. Racionalidad sustantiva. Administración pública. Licitaciones. Mejor contratación. 


\section{INTRODUÇÃO}

A maioria das pesquisas brasileiras que analisam a racionalidade nas organizações se baseia, segundo Santos e Serva (2013), na obra A nova ciência das organizações: uma reconceituação da riqueza das nações (GUERREIRO RAMOS, 1981). O entendimento daí decorrente coloca o indivíduo no centro das tomadas de decisão nas organizações, sendo necessário um mínimo de consenso social, do contrário, os objetivos organizacionais podem fracassar, pois as pessoas, em geral, deparam-se constantemente com a tensão entre a racionalidade substantiva e a instrumental.

Amparado em breve resgate das definições originais de Guerreiro Ramos (1981), o principal modelo de análise da racionalidade substantiva e instrumental adotado neste artigo foi elaborado por Serva (1997) e adotado posteriormente por diversos autores. Em 2012 havia pelo menos 17 trabalhos publicados (entre teses e dissertações) que adotaram, no todo ou em parte, as categorias e dimensões desse modelo (SANTOS e SERVA, 2013). Os estudos, no entanto, foram desenvolvidos a partir de organizações do mercado e do terceiro setor, não contemplando o tensionamento das racionalidades na administração pública. Visando a sistematizar os resultados dos estudos sobre racionalidade, Serva, Caitano, Santos et al. (2015) classificam os trabalhos em 2 grupos: a) primeira geração; e b) segunda geração. Tratam-se, respectivamente, das pesquisas empíricas realizadas com objetivo de identificar a racionalidade predominante na gestão, seguida por aquelas que promovem a tensão entre as racionalidades e a análise aprofundada das complexas relações.

No que tange às licitações públicas, em suma, o que se objetiva é a seleção da melhor proposta, consequentemente, a obtenção da melhor contratação pela administração pública (BANDEIRA DE MELLO, 2014). A obrigatoriedade de licitar, decorrente da previsão constitucional (BRASIL, 1988), pauta-se pelos princípios que regem o direito administrativo brasileiro, dentre os quais a legalidade, a impessoalidade, a moralidade, a publicidade e a eficiência. Então, o administrador público deve empenhar-se para que os interesses da coletividade sejam satisfeitos, podendo valer-se para isso de algumas prerrogativas, como a anulação ou revogação da licitação, desde que o ato esteja devidamente fundamentado, como previsto na lei de licitações (BRASIL, 1993). Embora os processos licitatórios tenham uma rotina prevista em lei, o ente público pode adequar as exigências de habilitação e qualificação técnica das empresas participantes, de acordo com as particularidades do objetivo que será contratado, uma vez que as condições definidas na legislação especial sejam obedecidas, sendo essa margem de ação denominada ato discricionário (MEIRELLES, 2016).

Foi nessa oportunidade decisória (margem discricionária) que a pesquisa desenvolvida buscou analisar a tensão entre a racionalidade substantiva e instrumental, pois se acredita ser oportuna a ampliação dos estudos sobre racionalidade junto à administração pública, já que é o mecanismo mediante o qual o governo obtém bens e serviços utilizados na execução e manutenção dos serviços públicos em geral, seja de forma direta ou indireta (DI PIETRO, 2016).

A pesquisa segue apoiada nas investigações realizadas por Santos (2012). Nesse caso, o autor observou que os entes públicos apresentam, por um lado, uma orientação racional instrumental, decorrente da expectativa de eficiência, e, por outro lado, uma orientação política relacionada à satisfação do interesse público, resultando na tensão entre as racionalidades a partir das práticas administrativas adotadas pelos gestores públicos. Destaca-se que, embora o ponto de partida seja a margem discricionária do gestor público, este artigo considerou a dinâmica entre o ato discricionário e vinculado como sendo o núcleo para compreensão da tensão entre as racionalidades.

Diante disso, este artigo teve por objetivo principal analisar o cotidiano das licitações públicas, em especial como os gestores públicos conduzem os processos decisórios, ou seja, qual foi a orientação adotada - substantiva e/ou instrumental. Apesar disso, o estudo não se restringiu a identificar a racionalidade preponderante, mas buscou compreender as inter-relações e a dinâmica da tensão, a partir das principais etapas dos certames, que vão desde a definição do objeto até a decisão final (resultado). Eis que se pode classificar como um trabalho científico de segunda geração (SERVA, CAITANO, SANTOS et al., 2015). Trata-se, ainda, de uma pesquisa qualitativa, de nível exploratório, desenvolvida a partir de análise documental e observação não participante, além da revisão bibliográfica pertinente ao tema. 


\section{RACIONALIDADE INSTRUMENTAL E RACIONALIDADE SUBSTANTIVA}

Notadamente, a obra A nova ciência das organizações: uma reconceituação da riqueza das nações (GUERREIRO RAMOS, 1981) foi um marco para os estudos organizacionais a partir da abordagem crítica no âmbito brasileiro. Embora se trate de um estudo fundado na ciência social em geral, o autor questiona a manutenção dos princípios que fundamentam as ciências econômica e administrativa predominantes na contemporaneidade. Mediante a indagação de conceitos, entendidos como aceitos, distorcidos ou simplesmente reproduzidos pela sociedade moderna, a discussão se volta tanto a questões relativas às organizações privadas como às públicas em geral. Desse modo, "a crítica de Guerreiro Ramos se destacou no campo dos estudos organizacionais por não somente se restringir à crítica em si, mas por também oferecer uma contribuição para o desenvolvimento de uma nova concepção teórica divergente das teorias tradicionais" (SERVA, CAITANO, SANTOS et al., 2015, p. 417).

Guerreiro Ramos (1981) faz uma crítica à razão moderna, devido à sua compatibilização com a estrutura normativa vigente, cuja linguagem distorcida tende a se tornar normal. Essa hegemonia poderia ser combatida a partir da racionalidade substantiva, que se encontra na natureza humana. Diferente da racionalidade formal weberiana, a proposta visa a ampliar a compreensão sobre possíveis contrapontos à lógica formal, inclusive enquanto regulador do processo econômico, uma vez que "a sociedade centrada no mercado é apenas uma forma recente de ordenação da vida humana" (SERVA, 1997, p. 30).

Souza e Ornelas (2015, p. 450) destacam que "Alberto Guerreiro Ramos compreendia as organizações como o instituto social cuja influência é notadamente decisiva na propagação do logos utilitarista". Eis um contraponto à teoria organizacional consagrada, no sentido de que a adaptação aos fatores externos não é uma alternativa válida. Assim, enquanto a correlação da teoria da organização se encontra na ciência social formal, infere Guerreiro Ramos (1981, p. 45) que "a contrapartida da nova ciência da organização é a ciência social substantiva".

Reforçando a discussão, mostra-se oportuno destacar que o pensamento habermasiano sugere o predomínio de processos orientados ao mútuo entendimento, cujo acordo deve ser obtido comunicativamente. Logo,

[...] enquanto que no agir estratégico um atua sobre o outro para ensejar a continuação desejada de uma interação, no agir comunicativo um é motivado racionalmente pelo outro para uma ação e adesão - e isso em virtude do efeito ilocucionário de comprometimento que a oferta de um ato de fala suscita (HABERMAS, 1989, p. 79).

Duas principais definições conceituais emergem na perspectiva sociológica: a) agir instrumental; e b) agir comunicativo, tratando-se, respectivamente, da constituição de mundo sistêmico e de mundo vivido (mundo da vida).

Em que pese destacar o interesse primordial de Habermas (1989) na construção de uma teoria crítica da sociedade, Guerreiro Ramos (1981, p. 20) faz a ressalva de que o autor frankfurtiano "apoia um tipo de psicologia motivacional que exclui o papel da razão na psique humana". Essa menção confronta uma das definições centrais da racionalidade substantiva, de que "a razão é conceito básico de qualquer ciência da sociedade e das organizações" (GUERREIRO RAMOS, 1981, p. 23). De todo modo, a racionalidade substantiva almeja transcender a estreita relação entre razão e cálculo, mediante julgamento éticovalorativo (SERVA, 1997).

O tensionamento entre a racionalidade instrumental e a racionalidade substantiva (SANTOS e SERVA, 2013), em especial no que se refere às organizações públicas, não adota necessariamente um padrão, pois os elementos que compõem cada uma são variáveis. Nesse sentido, "ambas as racionalidades são necessárias na gestão pública e se sustentam a partir da ética da responsabilidade e da ética da convicção" (SANTOS e SERVA, 2013, p. 15). Isso faz com que os estudos sobre o tema em questão se tornem ainda mais complexos, variando sobremaneira a depender de cada contexto, processo e decisão que envolva o gestor público, uma vez que os aspectos orientadores da conduta humana, em geral, não podem simplesmente ser excluídos.

Os estudos organizacionais que avaliam as racionalidades instrumental e substantiva têm identificado o predomínio daquela primeira, ao passo que a substantivação decorre justamente da oposição diante da adoção de modelos puramente instrumentais (CERRI, MARANHÃO e PEREIRA, 2017). Por outro lado, não significa necessariamente que a predominância de uma racionalidade implique redução da outra (SIQUEIRA, 2017). Dentre as características identificadas nesses fenômenos estão a "centralidade da comunicação e das relações sociais como dimensão política e arena da tensão entre racionalidades" 
(SIQUEIRA, 2017, p. 781). O diferencial está no compartilhamento da tomada de decisão, mediante relações interpessoais e ambientais, bem como sociais.

As divergências éticas, morais e filosóficas, somadas à luta de poder, são questões que também permeiam os espaços públicos e, portanto, contribuem para a formação de uma orientação puramente instrumental. A solução para essa situação seria adotar "um processo que leve a ações substantivas e que venham abrir espaços cada vez mais democráticos, participativos e dialógicos visando equilibrar as crescentes abordagens utilitaristas na gestão pública em detrimento dos impactos sociais esperados" (SOUSA e PAIVA JUNIOR, 2010, p. 114). Como salienta Sennett (2009), ao discorrer sobre a corrosão do caráter, os aspectos relacionados a lealdade, confiança, ajuda mútua e comprometimento são essenciais para o desenvolvimento de maneiras de agir coerentes com a condição humana. Tais questões não se restringem às empresas privadas, senão se acentuam na administração pública, uma vez que o gestor assume compromissos para além do entorno da organização, pois é, de fato, um administrador da sociedade (GUERREIRO RAMOS, 1983).

Ações substantivas e processos dialógicos são duas abordagens que se complementam (SERVA, 1997), uma vez que defendem a emancipação humana. Desse modo, a ação comunicativa (HABERMAS, 1989) e a racionalidade substantiva (GUERREIRO RAMOS, 1981) compõem a base teórica empregada no tensionamento em face da racionalidade instrumental. No entanto, adota-se a abordagem substantiva, já que é contemporânea à Escola de Frankfurt, em especial por se tratar de um estudo merecedor de maiores investigações, dado que em desenvolvimento (SERVA, CAITANO, SANTOS et al., 2015).

\section{ATO DISCRICIONÁRIO E COMPETÊNCIAS DO GESTOR PÚBLICO NO PÓS-REFORMA GERENCIAL}

Ao se orientar pelo tensionamento entre a racionalidade instrumental e a substantiva, este estudo buscou avaliar a parcela de decisões do gestor público, em face dos processos licitatórios, que lhe permitem adotar certa liberdade, ainda que dentro dos limites da lei. Em matéria dos princípios e fundamentos da administração pública, a discricionariedade decorre justamente de tal prerrogativa do administrador público (BANDEIRA DE MELLO, 2014). Embora não se trate de uma investigação jurídica, mostra-se importante ressaltar que, via de regra, a gestão pública é conduzida mediante um de seus princípios primordiais: a legalidade.

Do mesmo modo que não há uma regra para a definição das competências inerentes ao gestor público, importantes estudos (BUZATTO, 2012; REIS e MATOS, 2012; SILVA e ROQUETE, 2013; VALADÃO JÚNIOR, BUZATTO, MEDEIROS et al., 2017) têm sido desenvolvidos com a finalidade de identificar as principais fragilidades e, então, propor ações que contribuam com o aperfeiçoamento da administração pública. Ocorre que, embora existam mecanismos legais de controle dos atos da administração pública, em regra, eles se fundamentam mediante uma visão instrumentalista (HABERMAS, 1989), de aplicação de recursos e cumprimento do princípio da eficiência administrativa (BRESSER-PEREIRA, 2017), que, contudo, impede, em determinadas situações, que sejam mais bem avaliados os demais preceitos, tais como a razoabilidade e a proporcionalidade (BANDEIRA DE MELLO, 2014).

Uma pesquisa desenvolvida com o propósito de investigar as competências do gestor público (BUZATTO, 2012) aponta fragilidades relacionadas às questões de ordem política, fomento à cidadania e à democracia, bem como, a ausência de uma visão pensada de modo sustentável. Há, assim, a necessidade de aprimoramento da plena capacidade da equipe envolvida (SILVA, MOTA, DORNELA, et al., 2017), bem como uso de metodologias que possam ser praticadas com envolvimento dos atores.

Os poderes administrativos do gestor público nascem com a administração e diversificam-se a depender das demandas do serviço público, do interesse coletivo e dos objetivos perseguidos (MEIRELLES, 2016). Logo, não se confundem com poderes políticos, uma vez que "são verdadeiros instrumentos de trabalho, adequados à realização das tarefas administrativas. Daí a razão de serem considerados poderes instrumentais" (MEIRELLES, 2016, p. 137, grifo do autor).

Em decorrência da liberdade para a prática de atos diante do ordenamento jurídico, os poderes administrativos se classificam em vinculado e discricionário (BANDEIRA DE MELLO, 2014). Ainda assim, a discricionariedade não implica ampla liberdade de ação do gestor público, pois somente se dá se houver previsão legal. Não se confunde, dessa maneira, com o poder arbitrário. Em atenção ao interesse público, o gestor público deve, quando diante de uma questão pautada pela discricionariedade, adotar a decisão que melhor atenda aos interesses da administração pública, em benefício da coletividade administrada. 
As fragilidades das competências do gestor público, como aponta a literatura, são, por sua vez, contemporâneas à reforma gerencial do Estado, promovidas no Brasil em meados da década de 1990. Há, nesse sentido, uma lógica de eficiência das provisões decorrente das atividades da administração pública, que se originaram após o nascimento do Estado social na década de 1940 e se mantêm com a tentativa de superação da oposição neoliberal (BRESSER-PEREIRA, 2017). Ademais, "a reforma gerencial brasileira continua a prosperar, principalmente ao nível dos estados e dos grandes municípios, porque é neles que a gestão moderna é mais necessária" (BRESSER-PEREIRA, 2017, p. 152). Dentre os objetivos, busca-se maior eficiência dos serviços sociais, tanto que é, historicamente, a segunda reforma do Estado moderno, seguida pela reforma burocrática. Embora o consumo promovido pela administração pública (coletivo) seja entendido como mais eficiente do que o privado, ainda há deficiências no fornecimento de produtos e serviços de uso público.

\section{SELEÇÃO DA PROPOSTA MAIS VANTAJOSA}

A conclusão de Bresser-Pereira (2017, p. 154), ao analisar a reforma gerencial da administração pública brasileira no decorrer das duas décadas que se seguiram à sua implementação, é consubstanciada na legitimação e no fortalecimento do próprio Estado social, ou seja, "implica tornar coletiva ou pública a oferta dos serviços de educação, saúde e previdência social; e em tornar coletivo, ao invés de individual, seu consumo".

Vale ressaltar que, em decorrência do aumento do consumo por parte dos governos, também se acentuaram as contratações públicas em face da execução dos serviços públicos, e até para fins da manutenção da estrutura administrativa. Por outro lado, o artigo 37, XXI, da Constituição Federal (BRASIL, 1988) tornou obrigatória a realização de licitação pública para a contratação de obras, serviços, compra e alienação de bens - assim dispõe o referido dispositivo: "ressalvados os casos especificados na legislação, as obras, serviços, compras e alienações serão contratados mediante processo de licitação pública que assegure igualdade de condições a todos os concorrentes [...]".

Mediante esse procedimento administrativo, a administração pública "seleciona a proposta mais vantajosa para o contrato de seu interesse, inclusive o da promoção do desenvolvimento econômico sustentável” (MEIRELLES, 2016, p. 310).

Os atos do processo licitatório são, em regra, vinculantes tanto para a administração pública quanto para os licitantes (organizações participantes da disputa de preços) (BANDEIRA DE MELLO, 2014; MEIRELLES, 2016). Desse modo, o descumprimento dos princípios reguladores pode implicar anulação da escolha, quais sejam: a) formalidade; b) publicidade; c) igualdade entre licitantes; d) sigilo na apresentação das propostas; e) vinculação ao edital ou convite; f) julgamento objetivo; g) adjudicação compulsória ao vencedor; e h) probidade administrativa (BRASIL, 1993).

Uma vez definido o objeto licitado, vincula-se a administração pública a exigir, no ato convocatório (edital), a comprovação das organizações participantes de que cumprem com as condições jurídicas de habilitação, cujo rol de documentos, certidões e declarações encontra-se definido na Constituição Federal (BRASIL, 1988) e na Lei n. 8.666 (BRASIL, 1993). O mesmo vale para fins de verificação da qualificação técnica das licitantes.

Além dos procedimentos de habilitação jurídica e qualificação técnica das organizações, todo o processo licitatório deve promover o desenvolvimento nacional sustentável, como estabelece o artigo 3ㅇ da Lei n. 8.666 (BRASIL, 1993), "a licitação destina-se a garantir a observância do princípio constitucional da isonomia, a seleção da proposta mais vantajosa para a administração e a promoção do desenvolvimento nacional sustentável [...]". Trata-se do "fortalecimento de cadeias produtivas de bens e serviços domésticos, usando-se para esse fim, o poder da compra governamental” (MEIRELLES, 2016).

Por outro, em decorrência da complexidade de determinados objetos licitados, tanto em se tratando da contratação de serviços ou aquisição de bens, não raras vezes o gestor público se vê diante de uma situação que lhe exige proferir uma decisão, por óbvio, consubstanciada nos princípios norteadores das licitações, bem como da administração pública em geral (BANDEIRA DE MELLO, 2014). Em geral, tal situação ocorre na fase de organização do documento convocatório, denominada fase interna da licitação, uma vez que o entendimento majoritário da literatura vai no sentido de que a administração se vincula, de todo modo, às normas e condições do edital levado a público (SCHEIBLER e FAGANELLO, 2015).

A discricionariedade do gestor público não se confunde com a escolha da organização que será contratada (PEREIRA JÚNIOR, 2009), pois, do contrário, estar-se-ia negligenciando a real intenção da licitação, que é proporcionar a melhor contratação, 
mediante o estabelecimento de critérios que se pautem pelo fim a ser alcançado e pela garantia de que o licitante vencedor cumprirá com as obrigações assumidas. Essa margem de decisão, se empregada equivocadamente, ao mesmo tempo que amplia o rol de exigências no certame, prejudica a ampla participação e, consequentemente, reduz a oferta de propostas sem que, contudo, seja útil ao interesse público e ao objetivo perseguido. Em razão disso, "a regulamentação infraconstitucional apresenta um rol máximo de requisitos passíveis de serem exigidos para a comprovação da habilitação dos licitantes" (SCHEIBLER e FAGANELLO, 2015, p. 87).

\section{METODOLOGIA}

Para análise dos processos licitatórios, do ponto de vista ontoepistemológico, encontramo-nos no campo da fenomenologia, dada a necessidade de compreensão do mundo vivido pelos agentes públicos responsáveis por conduzir os certames. De acordo com Coltro (2000, p. 44), nesses casos se deve "considerar a experiência pura do sujeito-pesquisador, em situações de contatos face-a-face com os agentes observados", no intuito de obter uma observação mais contundente do fenômeno em estudo, do mesmo modo que requer maior tempo para execução. Embora existam pelo menos 6 tipos fenomenológicos (BOAVA e MACEDO, 2011), neste estudo se adota a fenomenologia descritiva, por representar a origem do movimento fenomenológico, ser reflexiva e ocupar-se das evidências obtidas com a pesquisa. Visando à elucidação das questões alusivas à natureza das experiências vividas, buscou-se analisar de que modo ocorre o tensionamento entre a racionalidade instrumental e substantiva no âmbito das decisões do gestor público, diante dos processos licitatórios.

Enquanto abordagem, a pesquisa se caracteriza como qualitativa (CHIZZOTTI, 2003), de nível exploratório, uma vez que os fenômenos da tensão entre as racionalidades no âmbito dos processos licitatórios apresentam questões ainda não elucidadas e igualmente complexas, em razão das relações interdisciplinares, destacando-se o conjunto de leis que rege os atos da administração pública.

Para a realização do estudo empírico, acompanharam-se três processos licitatórios realizados no âmbito da administração pública de um município do noroeste do Estado do Rio Grande do Sul, de modo remoto mediante as publicações oficiais do ente público e presencial, durante a realização das sessões de licitação. A escolha do local e da natureza do objeto licitado contou com avaliação prévia dos casos mais recorrentes no ramo de serviços públicos da região, bem como das constantes tentativas frustradas de licitação e contratação verificadas no âmbito de todo o Estado, conforme dados divulgados pela Federação das Associações de Municípios do Rio Grande do Sul (FAMURS) no final de 2015 (FAMURS, 2015).

A coleta de dados foi realizada mediante pesquisa documental, bibliográfica e observação não participante. Os documentos coletados e analisados compreendem termos de referência do objeto licitado, editais de abertura, decisões e julgamentos proferidos pelo gestor público no curso do processo, bem como as diligências decorrentes de impugnações e recursos apresentados pelos licitantes, além da legislação que orienta as compras públicas no âmbito nacional. Ao todo, analisaram-se na íntegra 3 processos de editais, publicados entre os anos de 2015 e 2019, para o mesmo objeto de contratação, sendo essa a delimitação temporal do estudo. A revisão bibliográfica abrangeu a revisão da literatura empregada na fundamentação teórica, bem como análise e discussão dos resultados. No que tange às observações, estas ocorreram mediante a condição de espectador das sessões públicas de julgamento das propostas, realizadas no segundo semestre de 2017 e no primeiro semestre de 2018 e 2019. Ocorre que embora a permanência de pessoas não envolvidas no certame seja assegurada por lei, por se tratar de ato público, aos pesquisadores não foi assegurado o direito de intervenção no curso das sessões, pois não compunham o rol de licitantes.

Diante disso, a investigação pode ser realizada mediante atividades de observação não participante, visando à compreensão das intervenções, discussões e decisões emanadas do gestor municipal, dos técnicos da administração pública e dos representantes das organizações licitantes, no curso dos processos administrativos analisados. Silva (2007) entende que, nesse caso, o pesquisador age como observador atento, com o objetivo de registrar o máximo de ocorrências com potencial de contribuir com o trabalho. Com isso, pode-se organizar uma descrição mais apurada dos sistemas simbólicos identificados e dos significados aos quais se associam. Para registro das reações dos envolvidos nos processos durante as sessões, utilizou-se diário de campo - onde foram anotados os diálogos e apontamentos relativos às categorias apresentadas no Quadro 2, para posterior análise à luz do referencial teórico, e documentos oficiais que nortearam os certames. 


\section{PROCESSOS LICITATÓRIOS ANALISADOS}

Ambos os processos licitatórios analisados foram desenvolvidos com o objetivo de contratar empresa especializada em serviços de saúde, para realizar a gestão e operacionalização de uma unidade de pronto atendimento 24 horas (UPA). As atividades incluíam o recrutamento e a seleção de pessoas; aquisição, manutenção e controle de materiais; organização de protocolos e controle de fluxos de atendimento; dentre outras ações inerentes às organizações de saúde que funcionam em caráter contínuo, sem interrupção, e atendem casos de urgência e emergência.

Até meados do ano de 2016, não havia sido realizado processo licitatório para a gestão da UPA nos padrões definidos pelo governo federal, razão pela qual o primeiro certame, ocorrido no ano de 2015 , não se revestia de maior complexidade, visto que as instalações funcionaram por um período, apenas como pronto atendimento de saúde municipal, não tendo sua qualificação reconhecida pelo Ministério da Saúde (MS). Ainda assim, houve impugnações, tendo um dos editais sido cancelado em virtude das inconformidades legais apontadas por organizações interessadas, que alegaram irregularidades e quebra da isonomia e da ampla concorrência.

Após apontamentos do órgão de controle, a administração municipal rompeu o contrato para gestão do pronto atendimento e firmou, no ano de 2017, um contrato emergencial, tendo como objeto a gestão da unidade de saúde nos padrões próprios de uma UPA, procedendo-se em seguida à publicação de 3 novos editais, uma vez que os 2 primeiros certames foram dados como fracassados, diante da inabilitação de ambas as organizações participantes, pois se entendeu que não cumpriam fielmente com as exigências editalícias. Nessa primeira oportunidade participaram 7 proponentes, ao passo que na segunda convocação o número se reduziu para 4 , sendo 3 no terceiro certame.

\section{QUADRO DE ANÁLISE}

Partindo do quadro de análise proposto por Serva (1997), o qual distingue os elementos da racionalidade instrumental e substantiva, elaborou-se um quadro específico para as investigações sobre as decisões proferidas pelo gestor público nos processos licitatórios analisados, composto por 5 categorias. Substituíram-se os processos organizacionais que causam tensão entre ambas as racionalidades pelas etapas dos processos licitatórios que, via de regra, são adotados por todos os entes da administração pública direta e indireta no Brasil.

Salienta-se que a divisão empregada não decorre necessariamente de uma abordagem doutrinária, mas representa de modo sucinto as fases analisadas. Para complementar o estudo foram utilizadas as categorias de análise propostas por Santos e Serva (2013), conforme o Quadro 1, visto que também versa sobre pesquisa realizada a partir da gestão pública.

\section{Quadro 1}

Tensão entre a racionalidade substantiva e instrumental

\begin{tabular}{|c|c|c|c|}
\hline & $\begin{array}{c}\text { Racionalidade } \\
\text { substantiva }\end{array}$ & Tensão & $\begin{array}{c}\text { Racionalidade } \\
\text { instrumental }\end{array}$ \\
\hline $\begin{array}{c}\text { Processo decisório } \\
\text { Políticas e práticas de gestão } \\
\text { Objetivos e metas } \\
\text { Efeitos } \\
\text { Pressões }\end{array}$ & $\begin{array}{l}\text { Autenticidade } \\
\text { Autonomia } \\
\text { Autorrealização } \\
\text { Entendimento } \\
\text { Julgamento ético } \\
\text { Satisfação Social }\end{array}$ & \multirow{2}{*}{$\begin{array}{c}\text { Características } \\
\text { organizacionais } \\
\text { Ausência de consenso } \\
\text { Forças de pressão e } \\
\text { influências } \\
\text { Inconformidade e } \\
\text { convicções } \\
\text { Preferências pessoais e } \\
\text { organizacionais }\end{array}$} & $\begin{array}{c}\text { Cálculo } \\
\text { Êxito e resultados } \\
\text { Fins } \\
\text { Maximização de } \\
\text { recursos } \\
\text { Rentabilidade } \\
\text { Utilidade }\end{array}$ \\
\hline $\begin{array}{c}\text { Valores e objetivos } \\
\text { Identidade e padrões } \\
\text { Origem, difusão e compartilhamento } \\
\text { Objetivos pessoais e objetivos } \\
\text { organizacionais Estímulo e realização }\end{array}$ & $\begin{array}{c}\text { Autenticidade } \\
\text { Autonomia } \\
\text { Autorrealização } \\
\text { Entendimento } \\
\text { Julgamento ético } \\
\text { Satisfação social } \\
\text { Valores emancipatórios }\end{array}$ & & $\begin{array}{c}\text { Desempenho } \\
\text { Exxito e resultados } \\
\text { Fins } \\
\text { Rentabilidade }\end{array}$ \\
\hline
\end{tabular}

Fonte: Santos e Serva (2013, p. 8). 
A tensão decorrente da análise dos processos decisórios, bem como dos valores e objetivos, possibilita, conforme o Quadro 1 (SANTOS e SERVA, 2013), reavaliar algumas das competências do gestor público identificadas em alguns estudos como deficientes (BUZATTO, 2012; REIS e MATOS, 2012). Desse modo, é possível discorrer sobre questões pontuais que envolvem a administração pública, em especial aquelas que são ponto de partida para muitas das atividades desempenhadas pelo gestor público. É o caso dos processos licitatórios, uma vez que antecedem a contratação das empresas responsáveis pelo fornecimento de bens e serviços aos governos, que, em grande parcela, impactam diretamente a qualidade dos serviços públicos.

\section{CATEGORIAS ANALISADAS}

O Quadro 2 apresenta as categorias analisadas e os respectivos elementos constitutivos, para ambas as racionalidades: substantiva e instrumental. A primeira permite constatar que deve ser considerada, para efeitos do objeto de estudo, a dinâmica existente entre ambas as racionalidades, decorrente da presença de princípios reguladores dos atos da administração pública, tais como: obrigação de licitar, eficiência e impessoalidade.

\section{Quadro 2}

\section{Categorias e dimensões das racionalidades substantiva e instrumental nos processos licitatórios analisados}

\begin{tabular}{|c|c|c|}
\hline Categoria & Racionalidade substantiva & Racionalidade instrumental \\
\hline Origem e definição do objeto licitado & Interesse coletivo & Determinação legal \\
\hline $\begin{array}{l}\text { Definição dos requisitos de } \\
\text { habilitação e qualificação }\end{array}$ & Entendimento & Dedução lógica \\
\hline $\begin{array}{c}\text { Julgamento das impugnações } \\
\text { e recursos }\end{array}$ & Pluralidade de propostas & $\begin{array}{c}\text { Eliminação de riscos, ação } \\
\text { calculista }\end{array}$ \\
\hline $\begin{array}{l}\text { Posição das empresas licitantes } \\
\text { no curso da sessão }\end{array}$ & $\begin{array}{l}\text { Avaliação das propostas } \\
\text { e disputa de preços }\end{array}$ & Eliminação de concorrentes \\
\hline Resultado do processo & Interesse público & Interesse privado/mercado \\
\hline
\end{tabular}

Fonte: Elaborado pelos autores.

A categoria origem e definição do objeto foi definida com vistas a representar em quais elementos se fundamentam as iniciativas do gestor público ao definir o objeto licitado. Embora tenha analisado que a obrigatoriedade de licitar é inafastável aos entes públicos, isso não significa que ela decorra necessariamente de uma determinação legal. Diferentemente, a orientação substantiva da administração pública resultaria em decisões oriundas do interesse coletivo, o que é diferente de mero cumprimento de uma determinação dos órgãos de controle, sob pena de responsabilização pessoal do gestor, diante de eventual descumprimento da determinação constitucional de licitar.

No caso analisado, verificou-se que a municipalidade dispunha de uma infraestrutura física construída com recursos do governo federal que, por não estar sendo empregada na prestação dos serviços para os quais se destinava, resultou na interferência dos órgãos de controle externo, inclusive do Ministério Público Federal (MPF). Houve, portanto, um processo decisório de utilidade (SANTOS e SERVA, 2013), pautado igualmente por valores e objetivos finalísticos, que não necessariamente representam a busca de melhorias na rede de serviços, bem como pela qualidade de vida da população beneficiada.

Para além das disposições legais que definem os requisitos de habilitação e qualificação das empresas participantes das licitações em geral, em ambos os processos analisados, a administração pública alternou exigências que não demonstram assegurar utilidade ao interesse público, em especial para que se obtivesse a melhor contratação. Nesse tocante, os editais exigiram registro e inscrição prévia das licitantes em distintos órgãos reguladores, sem que, contudo, houvesse eficácia em face do objeto a ser contratado. Um exemplo é a exigibilidade de inscrição junto ao Cadastro Nacional de Estabelecimentos de Saúde (CNES), uma vez que as atividades contratadas seriam desempenhadas em unidade de saúde distinta daquelas que a empresa licitante poderia ter em atividade. Ou seja, sem eficácia em face do objeto licitado. Esse critério foi umas das razões que resultou no fracasso dos certames, em virtude da não habilitação de pelo menos duas das empresas participantes.

Diferentemente, poderia o ente estabelecer que a vencedora deveria proceder imediatamente à inclusão da unidade pública administrada, no rol de estabelecimentos de responsabilidade dela, relacionando, para tanto, o rol de profissionais de saúde 
necessários para a execução das atividades contratadas. Nessa categoria há um fenômeno interessante, decorrente do tensionamento entre ambas as racionalidades, dado que as convicções e preferências pessoais tomaram frente do processo, impedindo uma avaliação mais substantiva da questão, ou seja, de entendimento e julgamento ético. A dedução lógica surge como o elemento que melhor descreve a decisão do gestor público, trata-se de uma visão que prejudica a avaliação pautada pela autonomia e pela emancipação coletiva (GUERREIRO RAMOS, 1981).

A implementação do controle social na gestão pública, incluindo os processos licitatórios, tal como sugerem Campos e Costa (2017), com base nas dimensões de interesse coletivo e nos pressupostos legais das compras públicas, teria uma função integradora e emancipadora. Nesse sentido, haveria melhor alocação dos recursos públicos. As melhorias nas percepções dos gestores públicos, como referido pelos autores, mostram-se cruciais, com base nos fenômenos identificados neste estudo, para a construção de espaços de inclusão, evitando-se que os processos licitatórios sejam instaurados meramente enquanto dever legal da administração pública, devendo ser entendidos como uma etapa do planejamento local.

O risco é de que os certames tenham, na origem, desvirtuamentos que priorizam interesses de mercado, ainda que intencionais, dado o baixo nível de entendimento dos atores envolvidos e, sobretudo, em razão da ausência de prévia deliberação participativa (PAZOS, OLAYA e ARIAS, 2017). O problema se intensifica caso não sejam identificadas as estratégias dos grupos fornecedores, que induzem o gestor público a adotar critérios contraditórios em relação à melhor contratação pública.

Também se observou nas discussões ocorridas nas sessões públicas que tal exigência sempre fora adotada e que outros entes também a adotam, muito embora até então não tivessem sido analisados os efeitos em face da obtenção da melhor contratação. Portanto, a dedução lógica identificada parte do pressuposto de que, ao exigir registro das licitantes em diversos órgãos, estaria a administração pública aferindo maior margem de segurança à gestão como um todo, o que é fruto da aspiração pelo êxito, decorrente da orientação mercadológica, tal como referem os estudos de primeira geração citados por Serva, Caitano, Santos et al. (2015).

Diante das exigências de habilitação e qualificação das empresas licitantes, como definido nos editais dos processos analisados, ocorreram impugnações, assim como recursos decorrentes das decisões proferidas pela autoridade da administração pública, nas sessões de julgamento das propostas. $O$ julgamento das impugnações e recursos ensejou, respectivamente, a suspensão e republicação dos editais de dois certames e a deserção das propostas do segundo, quando da realização da sessão. Somente com o terceiro certame foi possível obter a habilitação de propostas que, contudo, apresentaram inabilitações técnicas, diante do não cumprimento de requisitos definidos discricionariamente pelo gestor público.

Essa sequência de eventos resultou em contradições entre um edital e outro, pois enquanto algumas exigências foram abolidas, outras foram acrescidas, contribuindo para a redução do número de organizações participantes. Consequentemente, surgiu o problema da morosidade, em torno da contratação da empresa que ficaria responsável, a médio prazo, pela gestão da unidade de saúde. Ou seja, enquanto o ente analisou e julgou as impugnações e os recursos apresentados pelas empresas, prorrogou-se o início das atividades de ampliação dos serviços de saúde pública prestados à população. Além disso, o MPF voltou a questionar a não resolução da questão, exigindo agilidade por parte do gestor público.

Diante disso, as exigências decorrentes da ação racional instrumental se tornaram um empecilho para que a administração pública validasse as propostas que não atenderam aos requisitos exigidos com base na discricionariedade, tornando-se restrito o número de ofertas, logo, restringem-se as chances de obter a melhor contratação. Desse modo, as pressões decorrentes dos órgãos de controle externo se refletiram no receio de violações por parte do gestor em face das decisões tomadas. Muito embora o interesse público possa ter sido prejudicado, tal constatação somente poderia ser evidenciada mediante o julgamento ético, que, por conta do baixo nível de subjetividade, foi simplesmente ignorado no processo.

Desse modo, prevalece quanto a essa categoria a tentativa de eliminação de riscos, embora se tenha identificado a tensão entre ambas as racionalidades. Ocorre que tais riscos não estão necessariamente relacionados à execução dos serviços contratados pela administração pública, mas decorrem do receio de responsabilização pessoal do gestor, caso sobrevenha entendimento de que houve violação dos princípios da legalidade, impessoalidade e vinculação ao ato convocatório. Trata-se de uma conduta associada à individualidade, de cunho calculista, que se reflete nas ações dos sujeitos (SANTOS e SERVA, 2013).

O procedimento das licitações públicas varia de acordo com a modalidade adotada. No caso estudado, ambos os certames seguiram a forma denominada pregão presencial, cuja disputa entre os fornecedores ocorre mediante a apresentação de uma oferta inicial (proposta), seguida por lances (BANDEIRA DE MELLO, 2014). Diante disso, a categoria denominada posição das empresas licitantes no curso da sessão foi assim definida em decorrência de um fenômeno identificado durante as sessões. 
Trata-se da acentuada rivalidade entre um concorrente e outro, pautada pela busca da irregularidade documental em vez da vantagem decorrente do preço ofertado. Em nenhum dos processos analisados se verificou a involução de preços decorrente de sucessivos lances, o que é, de certa forma, o objetivo maior da licitação, ou seja, proporcionar a melhor contratação para a administração pública, tanto em termos técnicos quanto financeiros (BANDEIRA DE MELLO, 2014; MEIRELLES, 2016).

O estudo realizado por Reis e Cabral (2018, p. 107) corrobora esta discussão, ao destacar que mesmo nas licitações eletrônicas, em que se propicia maior participação de concorrentes e, consequentemente, redução de preços, "não há relação significativa entre o acirramento da concorrência entre os participantes e a celeridade na entrega". Isso reforça a prevalência da posição de competição entre as empresas, em detrimento do interesse público e da melhor contratação, uma vez que existem outras variáveis de desempenho a considerar, como a exequibilidade de preços e a capacidade de entrega da licitante vencedora (qualificação técnica).

A típica rivalidade de mercado, em que as organizações batalham pela sobrevivência a todo custo para eliminar os prováveis concorrentes, mostrou-se bastante presente nas manifestações de ambas as proponentes. Embora não se possa lançar qualquer objeção a tal comportamento, para os efeitos deste estudo, mostra-se importante destacar a provável relação desse fenômeno com as categorias iniciais de análise, confirmando, nesse caso, que o tensionamento entre as racionalidades substantiva e instrumental se desdobra tanto em benefícios quanto em prejuízos aos interesses da administração pública e da coletividade em geral. No entanto, existem condicionantes ensejadores desse resultado, destacando-se o entendimento e a autonomia (HABERMAS, 1989), como já mencionados, visto que a oferta de lances foi prejudicada pela diversidade de interpretações decorrente das exigências não bem compreendidas pelo ente público, mas que constara em ambos os editais. De acordo com Serva (1997, p. 28), "as ações de entendimento se mostraram indispensáveis para dar o tom da razão substantiva nos processos duros". Em média, as sessões tiveram cerca de 3 horas de duração e, ao final, não se chegou a um entendimento que atendesse satisfatoriamente ao interesse coletivo.

A quinta categoria, denominada resultado do processo, foi assim definida em razão de representar, sucintamente, a predominância das orientações de mercado, no entorno dos processos que envolveram tomadas de decisão do gestor público, ao longo do desenvolvimento da licitação. Nesse sentido, Tenório (2008) chama atenção para a provável predominância das estratégias típicas do mercado nas atividades promovidas pelas organizações do terceiro setor, o que também abrangeria a gestão pública. Em parte, tal fenômeno restou evidenciado no estudo em questão, pois não há garantia de que a administração pública obteve a melhor contratação, logo, de que os desafios e anseios de ordem social estejam de fato sendo atendidos.

Não se pode afirmar, todavia, que a vertente instrumental nas repartições públicas decorre unicamente das pressões oriundas do primeiro setor, mas que a gestão dos conflitos travados entre as questões éticas individuais e da própria sobrevivência organizacional (GUERREIRO RAMOS, 1981) sejam mediadas nas negociações entre o gestor público e os fornecedores, observando-se, de qualquer modo, os limites da discricionariedade administrativa. Há, portanto, prerrogativas da administração pública brasileira definidas no ordenamento jurídico que devem ser mais bem analisadas. Isso, todavia, exige que os estudos organizacionais a partir dos espaços públicos se intensifiquem e avancem mais (TENÓRIO, 2013).

\section{TENSIONAMENTO IDENTIFICADO NOS PROCESSOS LICITATÓRIOS}

Vale elucidar que os processos licitatórios nascem com a demanda pública, seguida pela decisão do gestor público, pela publicação do ato convocatório, pela realização do certame e pela definição da empresa vencedora que executará o contrato de serviços ou fornecimento de bens e equipamentos (BANDEIRA DE MELLO, 2014). Desse modo, analisa-se nesse item o tensionamento entre as racionalidades substantiva e instrumental, levando-se em conta o processo licitatório como um todo.

Partindo da análise das 5 categorias formuladas neste estudo, extraem-se os principais elementos que caracterizam o tensionamento entre as racionalidades no decorrer dos processos licitatórios. Como ilustrado na Figura 1, na medida em que há maior presença de tais elementos nas decisões do gestor público, maior é a aproximação com a abordagem instrumental. Desse modo, a margem discricionária permite que sejam desenvolvidas competências tanto de ordem substantiva quanto instrumental e isso pode alterar-se significativamente entre um ente público e outro. 
Figura 1

Dinâmica do tensionamento entre a racionalidade substantiva e instrumental nos processos de licitações públicas analisados

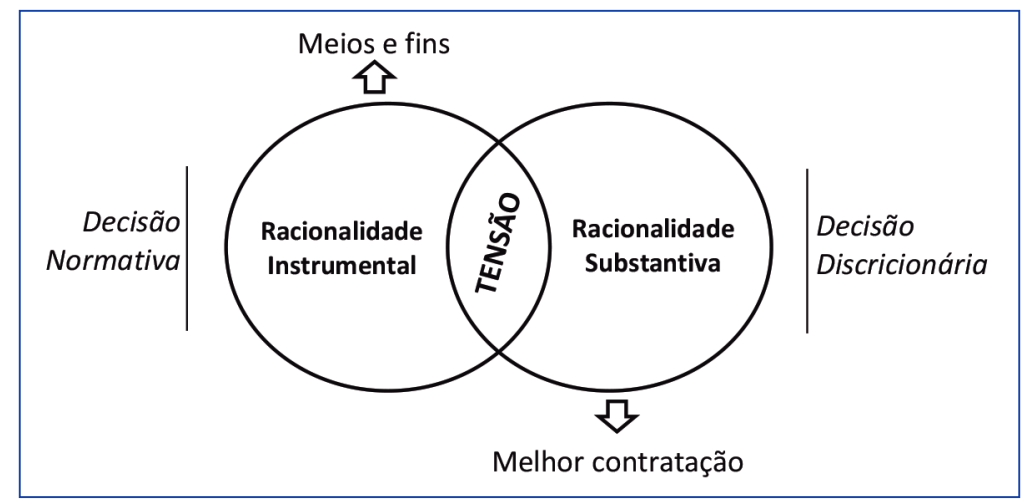

Fonte: Elaborada pelos autores.

Tal constatação confirma o que também foi identificado por Santos e Serva (2013, p. 15), ou seja, "na prática dos gestores [...] ambas as racionalidades são necessárias na gestão pública e se sustentam a partir da ética da responsabilidade e da ética da convicção". Resta analisar, em cada contexto, se esse predomínio ou aparecimento da racionalidade instrumental mantém relação ou não com alguns dos principais entraves apontados ao aperfeiçoamento da gestão pública e em quais situações podem ser identificados e examinados.

Na medida em que as decisões do gestor público deixam de lograr proveito da margem discricionária, pautando-se essencialmente pela orientação normativa ou, ainda, mesmo que discricionária, mantenham-se atreladas a meios e fins, torna-se prejudicado o tensionamento entre ambas as racionalidades, prevalecendo a lógica instrumental. Desse modo, as obrigações legais não podem ser interpretadas como óbice ao objetivo maior da melhor contratação, simplesmente porque isso seria suficiente para que a administração pública operasse em meio à burocracia. A reforma empreendida em meados da década de 1990 permanece em desenvolvimento (BRESSER-PEREIRA, 2017) e estudos como este demonstram que o espaço organizacional é uma das arenas de emancipação, sobretudo quando delibera sobre as questões com potencial de tratar das principais mazelas, sejam sociais ou de infraestrutura, que, em suma, influenciam o desenvolvimento geral da nação.

\section{CONSIDERAÇÕES FINAIS}

O estudo realizado possibilitou ampliar as investigações sobre racionalidades nas organizações, analisando nessa oportunidade a tensão entre a racionalidade substantiva e instrumental junto aos processos decisórios que envolvem as principais etapas das licitações públicas. Os resultados apontam que, embora o gestor público deva seguir um rol de determinações legais, há prerrogativas que lhe permitem agir de modo discricionário, sempre em defesa do interesse público, ainda assim pautado pelos limites do próprio ordenamento jurídico. Nesse sentido, pode-se inferir que o núcleo de tensionamento da racionalidade instrumental e substantiva reside na dinâmica legal-discricionária adotada pela administração pública. Logo, tanto os atos pautados estritamente pelo limite legal (vinculados) quanto aqueles amparados na margem discricionária podem ser consubstanciados na perspectiva instrumental. Ocorre que, em ambos os casos, a prerrogativa administrativa nem sempre é utilizada de modo consciente e emancipatório, com potencial para evitar as dicotomias decorrentes da racionalidade instrumental, pois exigem competências que são prejudicadas pela lógica da eficiência (incompreendida) e provisões bem delimitadas.

Busca-se identificar qual é o objetivo predeterminado da sociedade centrada no mercado, no caso as contratações públicas, o que pode representar um importante avanço para a compreensão dos entraves emergentes quando se vislumbra a racionalidade substantiva na prática administrativa. Partindo da obrigatoriedade de licitar definida pela Constituição Federal (BRASIL, 1988), as licitações públicas não fogem à discussão de 2 possíveis decisões: a) retardar a conclusão do processo de compra; ou b) apressar a conclusão do processo de compra. Situações como essas confirmam a necessidade de uma livre experiência da 
realidade e da articulação precisa da racionalidade substantiva, sob pena de levar à sua incompreensão, tal como defendido por Guerreiro Ramos (1981). Possivelmente, tal constatação constitui a maior contribuição do estudo realizado.

A administração pública brasileira iniciou uma reforma substancial na década de 1990, um processo que permanece em transformação. O potencial, no entanto, de promover ajustes que resultem em melhorias dos serviços públicos não se limita à eficiência e exige que se repense o termo do ponto de vista organizacional. Nesse sentido, entende-se que este artigo alcançou os objetivos aos quais se propôs, pois a observada tensão entre as racionalidades revelou fenômenos interessantes, que denotam a fragilidade dos processos licitatórios no que tange ao posicionamento adotado pelo gestor público. Há certa omissão e/ou aceitação tácita das pressões do mercado, que acabam prejudicando o sentido principal das licitações - a escolha da melhor contratação.

Sem ter a intenção de esgotar a discussão, em especial porque a pesquisa foi enquadrada como exploratória, entende-se que os estudos sobre racionalidade, consubstanciados em decisões no âmbito da gestão pública, devem avançar. Embora os gestores públicos detenham certa limitação quanto às tomadas de decisão, dado o aspecto da legalidade, pesquisas como esta viabilizam o entendimento de fenômenos imperceptíveis mediante outros métodos de investigação, nos quais a tensão entre as racionalidades substantiva e instrumental não é promovida. Neste estudo, pode-se identificar e propor um ponto de partida válido para a compreensão da tensão entre as racionalidades nas licitações públicas, tendo como núcleo a dinâmica legal-discricionária.

Esta pesquisa apresentou como limitação a abrangência de apenas uma contratação pública, embora o procedimento tenha se estendido por mais de 3 anos. Contudo, epistemologicamente, identificaram-se eventos que confirmam a pertinência dos estudos de racionalidades junto à gestão pública (SERVA, CAITANO, SANTOS et al., 2015) e os ganhos decorrentes para as ações dos gestores, sobretudo a possibilidade de propositura de novas categorias de análise. 


\section{REFERÊNCIAS}

BANDEIRA DE MELLO, C. A. Curso de direito administrativo. 30. ed. São Paulo: Malheiros, 2014.

BOAVA, L. T.; MACEDO, F. M. F. Contribuições da fenomenologia para os estudos organizacionais. Cadernos EBAPE.BR, Rio de Janeiro, v. 9, n. esp., p. 470-487, 2011.

BRASIL. Constituição (1988). Constituição da República Federativa do Brasil. Brasília, DF: Senado, 1988.

BRASIL. Lei n. 8.666, de 21 de junho de 1993. Regulamenta o art. 37, inciso XXI, da Constituição Federal, institui normas para licitações e contratos da Administração Pública e dá outras providências. Diário Oficial da União, Brasília, DF, 22 jun. 1993, Seção 1.

BRESSER-PEREIRA, L. C. Reforma gerencial e legitimação do estado social. Revista de Administração Pública, Rio de Janeiro, v. 51, n. 1, p. 147-156, 2017.

BUZATTO, T. R. E. Competências do gestor público: a relação entre a academia e as práticas. 2012. 159 f. Dissertação (Mestrado em Administração)-Universidade Federal de Uberlândia, Uberlândia, 2012.

CAMPOS, C. V.; COSTA, F. M. Determinantes para o cumprimento de prazo e preço em obras da educação: uma análise nos municípios capixabas. Revista de Administração Pública, Rio de Janeiro, v. 51, n. 5, p. 879-896, 2017.

CERRI, L. T.; MARANHÃO, C. M. S. A.; PEREIRA, J. J. As racionalidades substantiva e instrumental na prática organizacional: um olhar sobre Guerreiro Ramos e os estudos organizacionais. Revista Foco, v. 10, n. 2, p. 125-147, 2017.

CHIZZOTTI, A. Pesquisa em ciências humanas e sociais. São Paulo: Cortez, 2003.

COLTRO, A. A fenomenologia: um enfoque metodológico para além da modernidade. Caderno de Pesquisas em Administração, v. 1, n. 11, p. 37-45, 2000.

DI PIETRO, M. S. Z. Direito administrativo. 29. ed. Rio de Janeiro: Forense, 2016.

FEDERAÇÃO DAS ASSOCIAÇÕES DE MUNICÍPIOS DO RIO GRANDE DO SUL - FAMURS. Chega a 17 número de UPAs fechadas no RS por falta de recursos. 26 out. 2015. Disponível em: <http://www. famurs.com.br/noticias/chega-a-17-numero-de-upas-fechadas-nors-por-falta-de-recursos>. Acesso em: 1으 maio 2019.

GUERREIRO RAMOS, A. A nova ciência das organizações: uma reconceituação da riqueza das nações. Rio de Janeiro: Ed. FGV, 1981.

GUERREIRO RAMOS, A. Administração e contexto brasileiro: esboço de uma teoria geral da administração. Rio de Janeiro: Ed. FGV, 1983.

HABERMAS, J. Consciência moral e agir comunicativo. Rio de Janeiro: Tempo Brasileiro, 1989.

MEIRELLES, H. L. Direito administrativo brasileiro. 42. ed. São Paulo: Malheiros, 2016.

PAZOS, L. S.; OLAYA, A. P. G.; ARIAS, L. F. S. Estrategias de apropiación y desviación de recursos en el Sistema Municipal de Planeación de Santiago de Cali. Revista de Administração Pública, Rio de Janeio, v. 51, n. 6, p. 1023-1040, 2017.
PEREIRA JÚNIOR, J. T. Comentários à lei das licitações e contratações da administração pública. 8. ed. Rio de Janeiro: Renovar, 2009.

REIS, P. R. C.; CABRAL, S. Para além dos preços contratados: fatores determinantes da celeridade nas entregas de compras públicas eletrônicas. Revista de Administração Pública, Rio de Janeiro, v. 52, n. 1, p. 107-125, 2018.

REIS, R. C. S.; MATOS, C. R. N. Perfil do gestor público: elementos para formação e mudanças. In: CONFERÊNCIA INTERNACIONAL DE ESTRATÉGIA EM GESTÃO, EDUCAÇÃO E SISTEMAS DE INFORMAÇÃO, 1., 2012, Goiânia. Anais... Goiânia: Universidade Estadual de Goiás, 2012.

SANTOS, L. S. A tensão entre a racionalidade substantiva e a racionalidade instrumental na gestão pública: novos caminhos de um campo de estudos. 2012. 262 f. Dissertação (Mestrado em Administração) - Universidade Federal de Santa Catarina, Florianópolis, 2012.

SANTOS, L. S.; SERVA, M. A tensão entre a racionalidade substantiva e a racionalidade instrumental na gestão pública: novos caminhos de um campo de estudo. In: ENCONTRO DA ANPAD, 37., 2013. Rio de Janeiro. Anais... Rio de Janeiro: Anpad, 2013.

SCHEIBLER, J. L.; FAGANELLO, M. R. Direcionamento de licitações pela administração pública e mecanismos de controle da discricionariedade. FADERGS, v. 7, n. 2, p. 79-114, 2015.

SENNETT, R. A corrosão do caráter: as consequências pessoais do trabalho no novo capitalismo. 14. ed. Rio de Janeiro: Record, 2009.

SERVA, M. A racionalidade substantiva demonstrada na prática administrativa. Revista de Administração de Empresas, v. 37, n. 2, p. 18-30, 1997.

SERVA, M. et al. A análise da racionalidade nas organizações: um balanço do desenvolvimento de um campo de estudos no Brasil. Cadernos EBAPE.BR, Rio de Janeiro, v. 13, n. 3, 2015.

SILVA, A. B. A fenomenologia como método de pesquisa em estudos organizacionais. In: GODOI, C. K.; BANDEIRA-DE-MELO, R.; SILVA, A. B. (Org.). Pesquisa qualitativa em estudos organizacionais: paradigmas, estratégias e métodos. São Paulo: Saraiva, 2007. v. 1, p. 277-307.

SILVA A. G. F.; MOTA, L. A.; DORNELA, C. S. M; LACERDA, A. V. A relação entre Estado e políticas públicas: uma análise teórica sobre o caso brasileiros. Revista Debates, v. 11, n. 1, p. 25-42, jan./abr. 2017.

SILVA, Y. C.; ROQUETE, F. F. Competências do gestor em serviços de saúde: análise da produção científica, no período de 2001 a 2011. Revista de Administração em Saúde, v. 15, n. 58, p. 7-114, 2013.

SIQUEIRA, G. M. V. Tensão entre as racionalidades substantiva e instrumental: estudo de caso em uma ecovila no sul da Bahia. Cadernos EBAPE.BR, Rio de Janeiro, v. 15, n. 4, p. 768-782, 2017.

SOUSA, J.; PAIVA JUNIOR, F. G. Os novos tempos e a administração pública: as amarras da racionalidade instrumental e da regulação social. Revista Gestão Pública: Práticas e Desafios, v. 1, n. 1, p. 99-118, 2010. 
SOUZA, C. S.; ORNELAS, A. L. Alberto Guerreiro Ramos e a autonomia dos estudos organizacionais críticos brasileiros: escorços de uma trajetória intelectual. Cadernos EBAPE.BR, v. 13, n. 3, p. 438461, 2015.

TENÓRIO, F. G. Um espectro ronda o terceiro setor: o espectro do mercado. 3. ed. Ijuí, RS: Unijuí, 2008.
TENÓRIO, F. G. O pensamento organizacional sob o olhar de Janus. Ijuí, RS: Unijuí, 2013.

VALADÃO JÚNIOR, V. M. et al. Formação de competências do gestor público. Revista Capital Científico, v. 15, n. 1, 2017. Disponível em: <https://revistas.unicentro.br/index.php/capitalcientifico/article/ view/4310/3359>. Acesso em: 30 mar. 2020.

Vanilson Viana Cardoso

ORCID: https://orcid.org/0000-0003-2006-9227

Doutorando em Desenvolvimento Regional pela Universidade Regional do Noroeste do Estado do Rio Grande do Sul (UNIJUÍ) no Programa de Pós-Graduação Stricto Sensu em Desenvolvimento Regional; Mestre em Desenvolvimento Regional (PPGDR/UNIJUí); Advogado e Administrador, ljuí RS, Brasil. E-mail: vanilson-cardoso@hotmail.com

Airton Adelar Mueller

ORCID: https://orcid.org/0000-0001-6270-5856

Doutor em Sociologia pela Universidade Livre de Berlim, Alemanha; Professor no Programa de Pós-graduação, Mestrado e Doutorado em Desenvolvimento Regional na Universidade Regional do Noroeste do Estado do Rio Grande do Sul (PPGDR/UNIJUÍ), ljuí - RS, Brasil. E-mail: airton.mueller@unijui.edu.br 